| Case | Report |

\title{
Unexplained recurrent hematuria and clot retention following transurethral resection of the prostate
}

\author{
Mohammad Khairuzzaman, Provat Chandra Biswas, Md. Saiful Islam, S. M. Yunus Ali, Mohammed Rafiqul Islam and \\ Md. Sajid Hasan
}

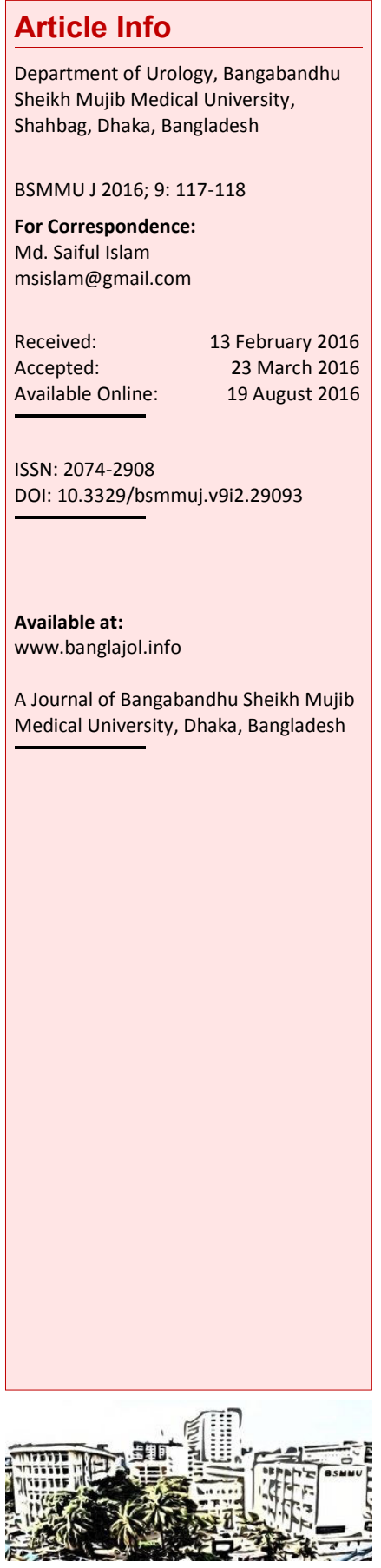

\begin{abstract}
Severe hemorrhage following a prostatectomy is a rare and serious complication. A 60-year-old male with recurrent hematuria and clot retention following transurethral resection of the prostate (TURP) which led to anemia presented at our department and was treated with repeated clot evacuation, fulguration and lastly re-resection and fulguration succeed to stop bleeding. At 18 months follow-up, the patient had recovered well. We concluded that re-resection and fulguration on fresh tissue without opening the venous sinusoids should be considered as one of the effective treatments of choice in recurrent hemorrhage following TURP.
\end{abstract}

\section{Introduction}

Transurethral resection of the prostate (TURP) is still the gold standard procedure in the operative management of benign prostatic hyperplasia (BPH). 1 Proper hemostasis is an important part of successful TURP. Severe prostatic bleeding after TURP is rare and usually managed by means of adequate bladder irrigation, traction of the catheter, pneumatic tamponade or endoscopic coagulation of bleeding point. Rarely, these procedures are ineffective and life-threatening situations may occur.? The incidence of blood loss requiring transfusion is reported to be $0.4-7.1 \%$, with rates declining with evolving technology despite an increasingly aged population having prostatic surgery. 3 Here, we report a case of recurrent hematuria following TURP and required massive blood transfusion.

\section{Case Report}

A 60-year-old man with history of ischemic heart disease, hypertension and diabetes mellitus underwent TURP under SAB at a local district private hospital. Per-operative and immediate post-operative period was unevenful. On $3^{\text {rd }}$ post-operative day, he developed hematuria and clot retention which was managed endoscopically. There was no active bleeding point found and irrigation was established and subsequently on $10^{\text {th }}$ post-operative day, he was released from the hospital with catheter with advice of bladder exercise. On $14^{\text {th }}$ post-operative day, the catheter was removed and patient voided well. But at mid night of that day, he again developed hematuria followed by clot retention and referred to a private hospital at Dhaka, where he underwent another three sessions of removal of clot and cauterization of oozing points of the prostatic bed. Patient remained well for 3-5 days. Then again bleeding and clot retention occurred. The same event occurred three times and every times he was managed by blood transfusion and endoscopic procedure but hematuria persisted.

Patient was finally referred to the Urology Department of Bangabandhu Sheikh Mujib Medical University (BSMMU). At BSMMU, cystoscopy revealed external urethral meatus (EUM), anterior urethra and veru were normal, bladder neck was wide open. There was organized large clot within urinary bladder. There was oozing from the prostatic bed. Then clot evacuation and hemostasis was done. Irrigation was established. But he again developed hematuria for which alum irrigation was tried but failed. Then again endoscopic clot evacuation and fulguration was performed. Then he was reevaluated.

His creatinine level was $0.9 \mathrm{mg} / \mathrm{dL}$. Prostatespecific antigen test was $3.7 \mathrm{ng} / \mathrm{mL}$. Bleeding time was $2 \mathrm{~min} 35 \mathrm{sec}$ and clotting time was 4 min $50 \mathrm{sec}$. $\mathrm{Hb}$ electrophoresis was $\mathrm{Hb} \mathrm{E}$ trait. Serum calcium level was $9.2 \mathrm{mg} / \mathrm{dL}$. Prothombin time was $12.8 \mathrm{sec}$ (normal 11-16 sec). Activated partial thromboplastin time was 33.9 sec (normal 20-40 sec).

Clot retraction test was normal. Contrast CT of the whole abdomen was done and the report 
was post-TURP state with evidence of residual prostatic parenchyma protruding into the bladder associated with blood clot into the urinary bladder. MR angiogram of the pelvic vessels, renal and pelvic DSA (Digital Substraction Angiogram) was done and the report was normal. Then a medical board was formed by hematologist, endocrinologist, cardiologist, urooncologist and urologist. The board gave opinion that the bleeding was not due to any hematolgical or systemic disease. It was due to local cause. Then the patient was kept under observation but again developed hematuria and clot retention. This time after clot evacuation, resection of residual prostatic bed and fulguration of bleeding point on freshly resected tissue was done. Following the last procedure, his hematuria stopped. The patient was discharged from hospital and no further bleeding occurred for the last 18 months.

\section{Discussion}

Recurrent bleeding after endoscopic prostatic surgery, although less common, is still a potentially life threatening complication. $\underline{3}$ The wide variety of treatments used for the control of severe bleeding from the lower urinary tract reflects the difficulty in controlling the bleeding by any one method alone. 4 Bleeding is the most important complication of TURP. 5,6 Massive hemorrhage due to endoscopic urologic surgery is not frequent 5 and is generally secondary to damage of major venous branches (venous lakes) and arteries or to pseudoaneurysm or arteriovenous fistula formation. Several factors concur in this event including a) size of the prostate (the larger the gland, the greater the amount of blood loss), b) obstruction which leads to venous engorgement, c) erections during the resection, d) hypertension, e) hematologic disorders, and f) skill of the resectionist. 6 This complication can be life threatening and management is always difficult. Treatment by conservative means (catheter traction, inflation of the catheter balloon, intraprostatic injection of vasopressin or other vasoactive agents) $\underline{6}$ is often unsuccessful, and endoscopic fulguration is the procedure of choice in these cases. When even this procedure is unable to stop the bleeding, more invasive means such as open revision with gauze tamponade of the prostatic fossa or bilateral extraperitoneal internal iliac ligation has been proposed. 6 $\underline{-8}$ In this case, we performed endoscopic resection of unhealthy prostatic tissue up to fresh tissue and coagulation of bleeding points.

\section{Conclusion}

Repeat resection and fulguration of bleeding points on fresh tissue may be helpful for controlling recurrent hematuria following TURP.

\section{Ethical Issue}

Written and signed informed consent from the patient was taken for publishing this case report.

\section{References}

1. Rassweiller J, Teber D, Kuntz R, Hofmann R. Complications of transurethral resection of prostate (TURP): Incidence, management and prevention. EAU. 2006; 50: 969-80.

2. Barbieri A, Simonazzi M, Marcato $C$ et al., Massive hematuria after transurethral resection of prostate: Management by imtra-arterial embolization. Urol Int. 2002; 69: 318-20.

3. Lynch M, Sriprasad S, Subramonian K, Thompson P. Postoperative haemorrhage following tranaurethral resection of prostate (TURP) and photoselective vaporization of the prostate (PVP). Ann R Coll Sur Engl. 2010; 92: 555-58.

4. Appleton DS, Sibley GNA and Doyle PT. Internal iliac artery embolisation for the control of severe bladder and prostate haemorrhage. BJU. 1998; 61: 4547.

5. Mebust WK, Holtgrewe, Cockett ATK, Peters PC, Writting Committee. Transurethral prostatectomy: Immediate and postoperative complications. A cooperative study of 13 participating institutions evaluating 3,885 patients. J Urol. 1989; 141: 243-47.

6. Faysal M. Angiographic management of postprostatectomy bleeding. J Urol. 1979; 122: 129-31.

7. Mitchell ME, Waltman AC, Athanasoulis CA, Kerr WS, Dretler SP. Control of massive prostatic bleeding with angiographic techniques. J Urol. 1976; 115: 692-95.

8. Weyher JE, Bradley WS. Control of post-TURP hemorrhage by bilateral ligation of hypogastric arteries. Am Surg. 1958; 24: 193. 